\title{
A Performance, Emission and Combustion Investigation on Hot Air Assisted Eucalyptus Oil Direct Injected Compression Ignition Engine
}

\author{
D.TAMILVENDHAN \\ Research Scholar, Department of Mechanical Engineering \\ Sri Chankarasekharendra Saraswathi Viswa Mahavidyalaya University, Enathur \\ Kancheepuram, TamilNadu, India
}

V.ILANGOVAN

Professor, Department of Mechanical Engineering, Karpagavinayagar college of engineering and technology Maduranthagam, Tamilnadu, India

Received: April 7, 2011

Accepted: April 22, 2011

doi:10.5539/mas.v5n4p53

\begin{abstract}
A diesel engine modified for eucalyptus oil direct injection (EuDI) has been tested to study eucalyptus oil behavior. Since the eucalyptus oil possesses low cetane number fails to auto ignite, the test engine was modified to supply hot air during suction stroke which helps to auto-ignite the injected eucalyptus oil. The engine with this facility was operated using eucalyptus oil under various load conditions and at various intake temperatures. The results of the investigation were proved that eucalyptus oil could be direct injectable in a regular diesel engine after little engine modification. This method showed almost same brake thermal efficiency (BTE) at full load compared to standard diesel operation. Except $\mathrm{NO}_{\mathrm{x}}$ emission other emissions were found closer to diesel baseline operation. This mode offered almost 50\% smoke free operation at all loads compared to standard diesel operation. Also this method successfully proved the complete replacement of diesel fuel by eucalyptus oil.
\end{abstract}

Keywords: Eucalyptus oil, Air preheating, Eucalyptus oil direct injection, Performance, Emission and combustion

\section{Introduction}

The increasing industrialization and modernization of the world led to a steep rise in the consumption and demand for the petroleum-based fuels every year. On the other hand, the fossil fuel combustion continually accumulating green house gases into atmosphere that is responsible for the global warming. Considering these disastrous effect, many alternative fuels have been identified in the past and tested successfully in the existing engines. However, these fuels need considerable engine modification. Most of the alternative bio-fuels identified today are proved to be a partial substitute for existing one due to its few undesirable fuel characteristics (Devan and Mahalakshmi, 2010). However, the various admission techniques experimented earlier are giving good solution to apply larger fraction of replacing fuel in the existing engine. The biological based alternative fuels called biofuels were identified well before the exploration of the other promising alternative fuels (Robert et al, 1995). The primary advantage of this fuel is renewable and ecofriendly. Generally, plants yield two types of oils namely triglyceride oil (TG oils) and turpene oil (light oil) of which, triglyceride oil is obtained from the plant seeds but turpene oil is obtained from all parts of the plant (Karthikeyan and Mahalakshmi, 2005). In addition, their availability from natural sources is estimated to be more than TG oil. This kind of oils are largely available in some plant species namely eucalyptus, pine tree etc. The present investigation used one such oil called eucalyptus oil in a regular DI diesel engine to study its performance and emission characteristics. The properties of eucalyptus oil fall in between the properties of petrol and diesel and few of them are also closer to that of diesel oil (Table 1). More specifically, the cetane number of eucalyptus oil falls in between diesel and petrol fuels. Hence, a complete replacement of diesel fuel is not possible (Karthikeyan and Mahalakshmi, 2007). However, the method used in the present investigation helped to use sole eucalyptus oil in a DI diesel engine.

\subsection{Literature Review}

This section reviews the various admission techniques tried by researchers for admitting larger fraction of high volatile, low cetane fuels in CI engines. Generally, octane fuels are suitable for SI engines and the cetane fuels are suitable for CI engines. However, many researchers have proved that the octane fuel of considerable fraction can also be driving the CI engine in association with high cetane fuel. A performance and emission test was conducted on a dual fuel engine using propane and diesel fuel (Jorge and Barata, 1995). It is reported that, upto $90 \%$ of the diesel fuel energy input was replaced with propane gas without any loss of thermal efficiency. He also reported that this engine emits more $\mathrm{CO}$ and less $\mathrm{NO}_{\mathrm{x}}$ at all load conditions than that of standard diesel operation. The performance and emission characteristics were examined on dual fuel engine fuelled with 
jatropha oil and orange oil (Senthilkumar et al, 2001). Their results showed that the induction of orange oil reduces smoke and NO emission and improves thermal efficiency with all pilot fuels.

Ethanol direct injected, multi spark assisted diesel engine (SADE) is developed to study the combustion and emission performance of ethanol (Ubong, 1990). SADE offers superior combustion characteristics at higher loads than that of conventional turbocharged diesel engine. It was reported that this engine burns leaner at all operational limits and does not require throttling of inlet air. It was also reported that this engine emits near zero smoke emission at all load conditions and operated smoothly without any components failure up to 176.5 hours of engine operation. A new concept piston (a cetane improving technology) for alcohol direct injection and combustion in high compression engines was developed (Jiang and Andrew, 1996). Authors introduced a new concept piston called Sonex Combustion System (SCS) for providing self-ignition to the injected alcohol. It works on the principle of pre-ignition by utilizing active chemical species produced from partial oxidation process. It was reported that the engine operated successfully using ethanol and methanol without any ignition assistance at higher loads. However, at lighter loads, preheated air intake was provided to auto-ignite the injected alcohol. This engine was operated with higher $\mathrm{CO}$ and $\mathrm{HC}$ and near zero smoke emission compared to diesel baseline operation. An experimental investigation on DI diesel engine was attempted using minimally processed methanol to study the combustion and emission characteristics (Thomas et al, 1994). In this work, a minimally processed methanol was introduced into the engine through regular diesel injection system and the preheated air was inducted through inlet manifold. The hot air supplied to the engine helps to self-ignite the injected methanol. It was reported that the engine was operated with very low smoke and $\mathrm{NO}_{\mathrm{x}}$ emissions at all loads. An experiment was conducted on hot air assisted turpentine in DI diesel engine to study $\mathrm{BTE}, \mathrm{NO}_{\mathrm{x}}$ emission and smoke emission (Karthikeyan et al, 2010). In this work, 50\% smoke free operation compared to diesel fuel is observed at all loads.

\subsection{Eucalyptus oil}

Eucalyptus oil (cineole) is the generic name for distilled oil from the leaf of Eucalyptus, a genus of the plant family Myrtaceae native to Australia and cultivated worldwide. The leaves of selected Eucalyptus species are steam distilled to extract eucalyptus oil. The main chemical components of eucalyptus oil are $a$-pinene, $b$-pinene, a-phellandrene, 1,8-cineole, limonene, terpinen-4-ol, aromadendrene, epiglobulol, piperitone and globulol. Eucalyptus is a tall evergreen tree. It attains the height of more than 100 meter. The adult leaves are 15 to $30 \mathrm{~cm}$ long and 2 to $5 \mathrm{~cm}$ broad. Eucalyptus oil has a history of wide application, as a pharmaceutical, antiseptic, repellent, flouring, fragrance and industrial uses. The cineole (eucalyptol) based oils can also be used as an insect repellent and biopesticide. Eucalyptus oil has been used as an effective way of killing dust mites.

\section{Experimental setup}

The engine setup shown in Figure (1) used for experimental investigation is a single cylinder, air cooled, vertical and direct injection diesel engine. It is capable of developing $4.4 \mathrm{~kW}$ at a constant speed of $1500 \mathrm{rpm}$ and coupled to an eddy current dynamometer. The inlet side of the engine consists of anti-pulsating drum, air heater and air temperature measuring device. The exhaust side of the engine consists of Exhaust gas temperature (EGT) indicator, exhaust gas analyzer and smoke sampler. This set-up also consists of two separate fuel measuring devices for measuring diesel oil and eucalyptus oil separately. A crank angle encoder and a pressure pickup attached with the engine helps to acquire cylinder pressure and crank angle data via a 64 bit DAQ.

\section{Methodology}

Basically, eucalyptus oil is a low cetane fuel and hence, it has no ability to auto-ignite in a compression ignition engine. However, the present method utilizes $100 \%$ eucalyptus oil in a DI diesel engine after little engine modification. The only factor that prevents eucalyptus oil direct injection in $\mathrm{CI}$ engine is its higher self-ignition temperature. To overcome this, the heat content of the air must be maintained sufficiently high after adiabatic compression. Therefore, in the present work an air-preheater is located in the inlet side of the engine. It helps to raise the heat content of the air inside the cylinder and created a conducive ambient for self-ignition of injected eucalyptus oil. The quantity of preheat required for the intake air is more depends upon the load condition of the engine. That is, the engine requires more preheat at starting, idling and at lower loads but it requires less preheat at higher loads and peak loads.

\section{Results and Discussion}

\subsection{Determination of optimum Injection timing}

The injection timing of the fuel also determines the performance of the engine. Hence, the suitable injection timing that gives maximum performance has been identified first. The test engine was maintained at various injection timings and then intake air temperature was changed in step of $5^{\circ} \mathrm{C}$. At each step of intake temperature the BTE was calculated. The timing that requires low preheat temperature was considered as optimum injection timing for the whole work. Figure 2 shows the change in BTE with respect to intake temperature at various injection timing. 
From Figure 2, it is observed that the brake thermal efficiency increases with intake temperature, reaches maximum and then decreases. Also, it is observed that the maximum BTE of various injection timings occurs at various intake temperatures. However, the low intake temperature is preferred because it utilizes less external heat. The optimum injection timing that requires low intake temperature was $27^{\circ} \mathrm{BTDC}$.

\subsection{Determination of optimum intake temperature}

The intake temperature also plays a vital role in production of peak pressure and BTE. When intake temperature changes the ignition delay changes and causes a change in the occurrence of peak pressure. Hence, the optimum intake temperature that gives maximum performance was identified next to injection timing.

\subsubsection{Brake Thermal Efficiency}

Figure 3 shows the effect of intake temperature on brake thermal efficiency at various loads. As it is discussed earlier that intake temperature assists auto ignition. The variation of intake temperature affects the timing of auto ignition and peak pressure produced.

It also shows that the brake thermal efficiency increases with increase in intake temperature, reaches a maximum and thereafter decreases considerably at all loads. The increase in intake temperature reduces ignition delay and advances the occurrence of peak pressure. This provides more time for heat utilization. This is the main reason for rising trend of brake thermal efficiency. When the intake temperature increases further, the brake thermal efficiency falls due to the fact that eucalyptus oil burns in diffusion burning phase. The high intake temperature reduces the volumetric efficiency and causes scarcity of oxygen. This leads to reduced peak pressure and sluggish burning. This could be the reason for low brake thermal efficiency at high intake temperature.

It is also seen from the figure that the optimum intake temperature decreases with load. This is due to change in cylinder temperature with respect to load. That is at higher loads, due to burning of more fuel, the cylinder was maintained at higher temperature and hence, these loads require comparatively low intake temperature.

\subsubsection{Volumetric efficiency}

Figure 4 shows the variation of volumetric efficiency with intake temperature at various loads. The volumetric efficiency follows the decreasing trend with increase in intake temperature. It may be noted that the volumetric efficiency is a function of intake temperature and temperature of retained exhaust gas. However it is more influenced by intake temperature.

The increase in intake temperature decreases air density and causes low volumetric efficiency. Also, the increase in intake temperature extends the duration of combustion and causes the retention of high temperature exhaust gas inside the cylinder.

\subsection{Comparison of EuDI operation with standard diesel operation}

This section compares the results of EuDI mode with standard diesel operation. EuDI mode experiments have been conducted at optimum injection timing and at optimum intake temperature.

\subsubsection{Brake Thermal Efficiency}

Figure 5 compares the brake thermal efficiency of EuDI mode with standard diesel operation. The brake thermal efficiency of EuDI mode is comparatively lower than standard diesel operation except at full load. This is mainly due to the reduction of heater contribution with respect to increase in load. More heater contribution was required at lighter loads and less heater contribution was required at higher loads. This is the reason for rising trend of brake thermal efficiency at higher loads.

However, eucalyptus oil properties such as higher heat content, higher volatility and lower viscosity were considerably contributed for the achievement of higher BTE at full load. The brake thermal efficiency of EuDI mode at full load is $30.3 \%$, which is $1 \%$ higher than standard diesel operation.

\subsubsection{Volumetric efficiency}

Figure 6 compares the volumetric efficiency of EuDI mode with standard diesel operation. The figure shows increasing trend of volumetric efficiency for EuDI mode. This is due to reduction of intake temperature with respect to increase in load. The increase in load increases the fuel consumption and yields hot combustion chamber. Thus the same heat input may not be required for the next load to self-ignite the injected fuel. Therefore the heat input to the intake air decreases when load increases. Thus the volumetric efficiency of EuDI mode increases when the load increases. The volumetric efficiency of EuDI mode at no load is $80 \%$ and at full load is $83 \%$.

\subsubsection{CO Emission}

Figure 7 compares the $\mathrm{CO}$ emission of EuDI mode with standard diesel operation. The $\mathrm{CO}$ emission of EuDI mode is closer to that of standard diesel operation at all loads, except at full load. More fuel burning and relatively lesser availability of oxygen at the time of full load were the main reasons for higher production of $\mathrm{CO}$ at full load. The quench layer of charge near the wall due to reduced flame speed could also contribute sufficiently for the higher $\mathrm{CO}$ emission at full load. 


\subsubsection{HC Emission}

Figure 8 compares the HC emission of EuDI mode with standard diesel operation. From the figure it is observed that the HC emission of EuDI mode is lower than that of standard diesel operation at all loads. This trend attributes to combustion of high volatile eucalyptus oil in high compression and high temperature ambient. Also, the simple molecular structure and unstable nature of eucalyptus oil helps to combust the mixture without leaving unburnt hydro carbon. This is also one of the reasons for lower HC emission.

\subsection{5 $\mathrm{NO}_{\mathrm{x}}$ Emission}

Figure 9 compares the $\mathrm{NO}_{\mathrm{x}}$ emission of EuDI mode with standard diesel operation. The $\mathrm{NO}_{\mathrm{x}}$ emission of EuDI mode is higher than that of reference fuel at all loads. This is due to the production of higher combustion temperature during eucalyptus oil burning. Basically, eucalyptus oil is a volatile and low viscous fuel. Hence, it burns comparatively quicker than reference fuel and releases heat in a shorter duration. This causes higher combustion temperature and produces more $\mathrm{NO}_{\mathrm{x}}$ compounds than the standard diesel operation.

\subsubsection{Smoke Intensity}

Figure10 compares the smoke emissions of EuDI mode with standard diesel operation at various loads. The production of higher combustion temperature due to the rapid burning of volatile eucalyptus oil is the main reason for smoke free exhaust. The unstable nature and simple molecular structure of eucalyptus oil causes rapid oxidation and smoke free operation. This mode offered approximately $45 \%$ reduced smoke emission than that of standard diesel operation.

\subsubsection{Ignition delay}

Figure 11 compares the cylinder pressure diagram of EuDI mode with standard diesel operation at full load. It shows the combustion of eucalyptus oil occurred approximately 4 degrees later than standard diesel operation and produced peak pressure 5 degrees after TDC.

Figure 12 indicates the variation of ignition delay with engine load. The ignition delay of EuDI mode is higher than that of reference fuel at all loads. This is due to the instantaneous reduction of charge temperature as a result of evaporative cooling of eucalyptus oil. The ignition delay of EuDI mode at full load is 12 degrees which is 3 degrees higher than that of standard diesel operation.

\subsubsection{Net Heat release rate}

Figure 13 compares the net heat release rate of EuDI mode with the standard diesel operation. From the figure it is observed that the heat release rate of EuDI mode is almost similar to reference fuel. However, there is a marginal deviation in peak values of heat release rate and burn duration. The figure also shows the combustion of eucalyptus oil occurs approximately 3-4 degrees later than standard diesel operation. This is due to higher latent heat of vaporization and higher volatility of the injected eucalyptus oil. Hence, in this mode, unlike standard diesel operation more fuel burns in premixed phase of combustion. This is the main reason for production of higher peak pressure, shorter burn duration and higher rate of pressure rise at full load.

\section{Conclusion}

Based on the experimental investigations conducted on a single cylinder diesel engine modified for eucalyptus oil direct injection the following major conclusions were arrived.

1) Results showed that the direct injection of eucalyptus oil in a regular diesel engine is possible after little engine modification.

2) BTE of EuDI mode was found equal to that of standard diesel operation at full load.

3) Emissions like $\mathrm{CO}$ and $\mathrm{HC}$ were not adversely increased.

4) $\mathrm{NO}_{\mathrm{x}}$ emission of EuDI mode was found higher than that of diesel baseline operation at all loads.

5) Almost 50\% smoke free operation was achieved with EuDI mode at heavier loads.

From the obtained results it is proved that the sole fueling of eucalyptus oil in a DI diesel engine is possible with the significant engine modification and operational procedure.

\section{References}

Devan.P.K, and Mahalakshmi.N.V. (2010). Combustion, Emission and Performance Characteristics of Diesel engine Fueled with Eucalyptus oil with an Ignition Enhancer, International Journal of Green Energy, Energy and Environment, Vol.1, No.1, April 2010,pp. 40-49.

Jiang Lu and Andrew A. pouring. (1996). 'Development of a New Concept Piston for Alcohol Fuel Use in a CI Engine', SAE Trans., 961078, pp 13-27,http://dx.doi.org/ 10.4271/961078

Jorge M.M. Barata. (1995). 'Performance and Emission of a Duel Fueled DI Diesel Engine', SAE Trans., 952364, pp 1-7, http://dx.doi.org/10.4271/952364 
Karthikeyan R. and Mahalakshmi N.V. (2005). 'Performance and emission characteristics of four stroke DI diesel engine fueled with turpentine diesel blends', Proceedings of the ICEF2005 ASME Internal Combustion Engine Division 2005 Fall Technical Conference, Sep 11-14, 2005, Ottawa, Canada.

Karthikeyan R. and Mahalakshmi N.V. (2007). 'Performance and emission characteristics of a turpentine-diesel dual fuel engine', Energy the International Journal, Vol. 32, No. 7, July 2007, pp. 1202-1209. http://dx.doi.org/10.1016/j.energy.2006.07.021

Karthikeyan.R,Nallusamy.N,Alagumoorthi.N,Ilangovan.V.A detailed experimental investigation on hot air assisted turpentine direct injected compression ignition engine. International journal of engineering science and technology.Vol.2(10),2010,5034-5049

Robert J. Last, Micheal Kruger, Manfred Durnholz. (1995). Emissions and Performance Characteristics of A 4Stroke, Direct Injected Diesel Engine Fueled With Blends of Biodiesel and Low Sulfur Diesel Fuel, SAE Trans., 950054, pp 1-13, http://dx.doi.org/10.4271/950054

Senthil Kumar. M, Ramesh. A and Nagalingam. B. (2001). Experimental Investigations on a Jatropa Oil Methanol Duel Fuel Engine, SAE Trans., 2001-01-0153. http://dx.doi.org/10.4271/2001-01-0153

Thomas w. Ryan III, Milan Maymur, Dale ott, LaViolette R. A and McDowall R. D. (1994). Combustion and Emission Characteristics of Minimally Processed Methanol in a Diesel Engine without Ignition Assist, $S A E$ Trans., 940326, pp 1-27, http://dx.doi.org/10.4271/940326

Ubong E. U. (1990). Development of an Ethanol D.I. Spark Assisted Diesel Engine. (SADE). SAE Trans 901567 , pp1-11. http://dx.doi.org/ 10.4271/901567

Table 1. Physical and chemical properties of eucalyptus oil

\begin{tabular}{|l|l|l|l|}
\hline Properties & Gasoline & Diesel & Eucalyptus oil \\
\hline Formula & $\mathrm{C}_{4}$ to $\mathrm{C}_{12}$ & $\mathrm{C}_{8}$ to $\mathrm{C}_{25}$ & $\mathrm{C}_{10} \mathrm{H}_{18} \mathrm{O}$ \\
\hline Molecular Weight & $100-140$ & $200-240$ & 154.25 \\
\hline $\begin{array}{l}\text { Composition } \\
\% \mathrm{Wt}\end{array}$ & $\mathrm{C} 88 \mathrm{H} \quad 15$ & $\mathrm{C} \quad 87 \mathrm{H} \quad 16$ & - \\
\hline $\begin{array}{l}\text { Density } \\
\mathrm{kg} / \mathrm{m} 3\end{array}$ & 780 & 830 & 913 \\
\hline Specific Gravity & 0.78 & 0.83 & 0.918 \\
\hline $\begin{array}{l}\text { Boiling Point } \\
{ }^{\circ} \mathrm{C}\end{array}$ & $30-220$ & $180-340$ & 175 \\
\hline $\begin{array}{l}\text { Viscosity } \\
\mathrm{c} \mathrm{St}\end{array}$ & 0.4 & $3-4$ & 2.0 \\
\hline $\begin{array}{l}\text { Latent Heat of Vaporization } \\
\mathrm{kJ} / \mathrm{kg}\end{array}$ & 350 & 230 & 305 \\
\hline $\begin{array}{l}\text { Lower Heating Value } \\
\mathrm{kJ} / \mathrm{kg}\end{array}$ & 43,890 & 42,700 & 43,270 \\
\hline $\begin{array}{l}\text { Flash Point } \\
{ }^{\circ} \mathrm{C}\end{array}$ & -43 & 74 & 53 \\
\hline $\begin{array}{l}\text { Auto Ignition Temperature } \\
{ }^{\circ} \mathrm{C}\end{array}$ & $300-450$ & 250 & $300-330$ \\
\hline $\begin{array}{l}\text { Flammability limit } \\
\% \text { Volume }\end{array}$ & 1.4 & 1.0 & 0.8 \\
\hline Cetane Number & & $40-55$ & \\
\hline
\end{tabular}




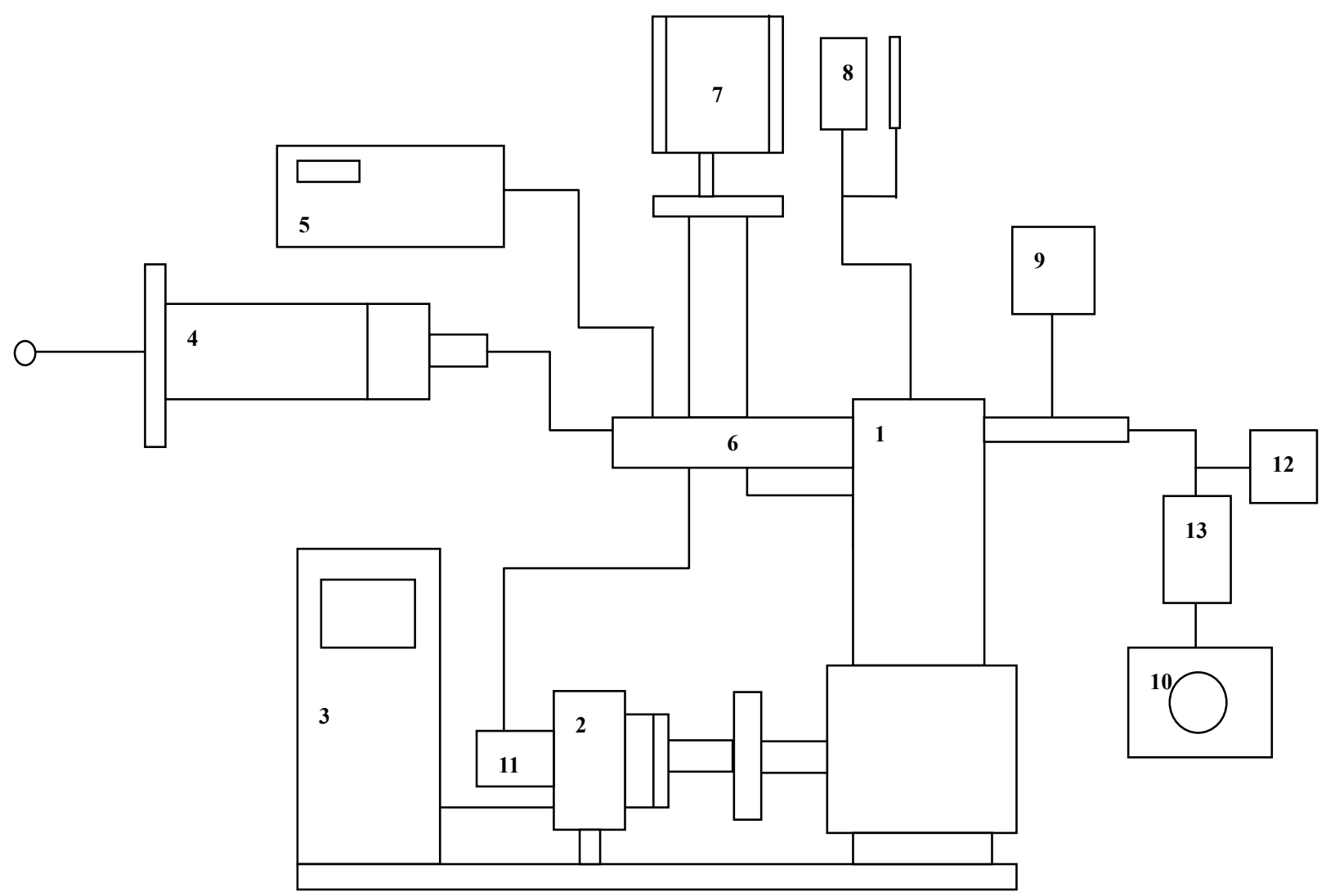

Figure 1. Experimental set up

1.Diesel engine,2.Eddy current dynamometer,3.Dynamometer control,4.Smoke sampling pump,5.Gas analyzer,6.Exhaust pipe,7.P-IV computer with DAQ,8.EU oil,9.Air inlet temperature indicator,10.Anti pulsating drum,11.Crank angle encoder,12.Energy meter. 13. Air preheater

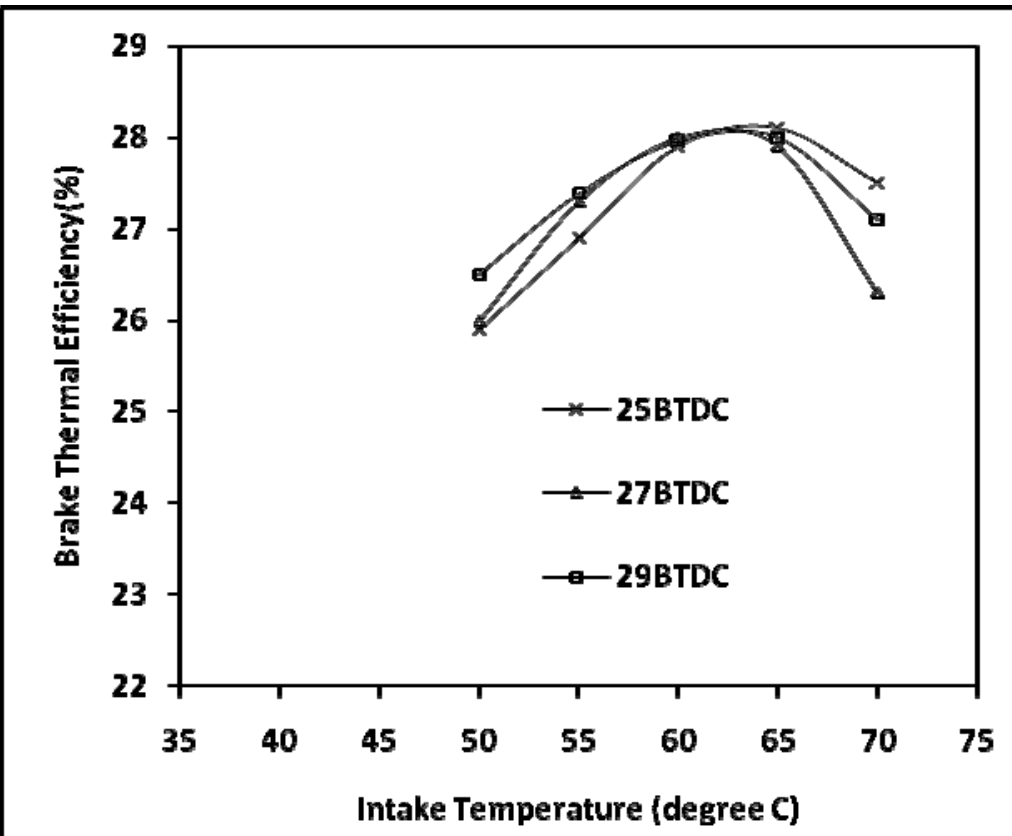

Figure 2. Variation of Brake thermal efficiency with intake temperature for various injection timing at $75 \%$ of full load 


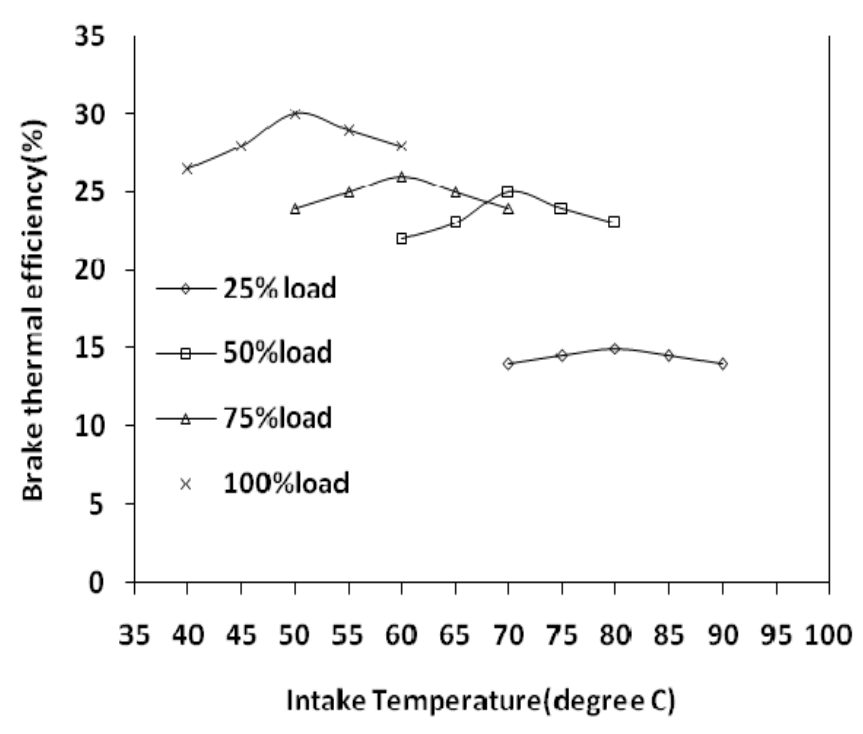

Figure 3. Variation of brake thermal efficiency with intake temperature

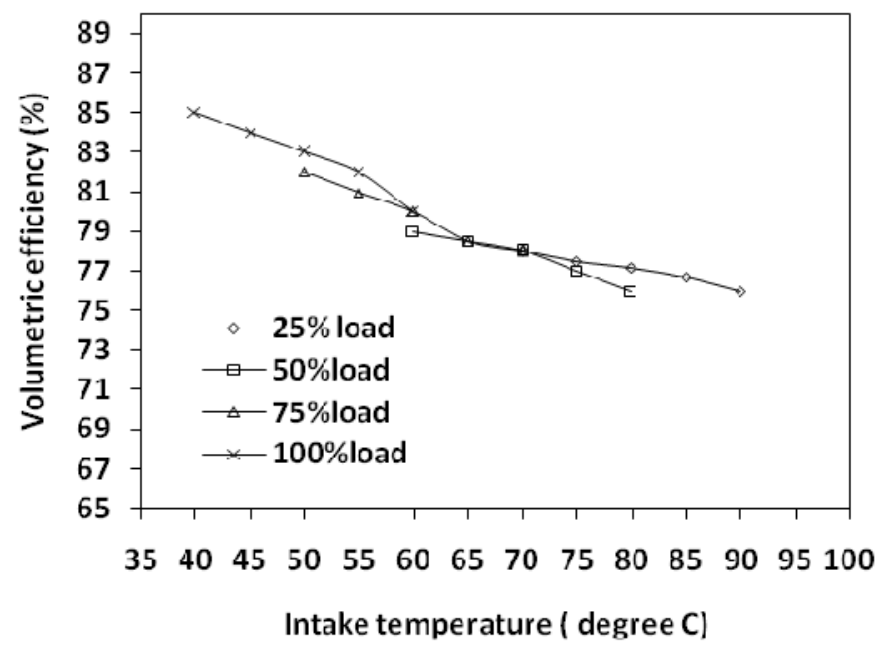

Figure 4. Variation of volumetric efficiency with intake temperature

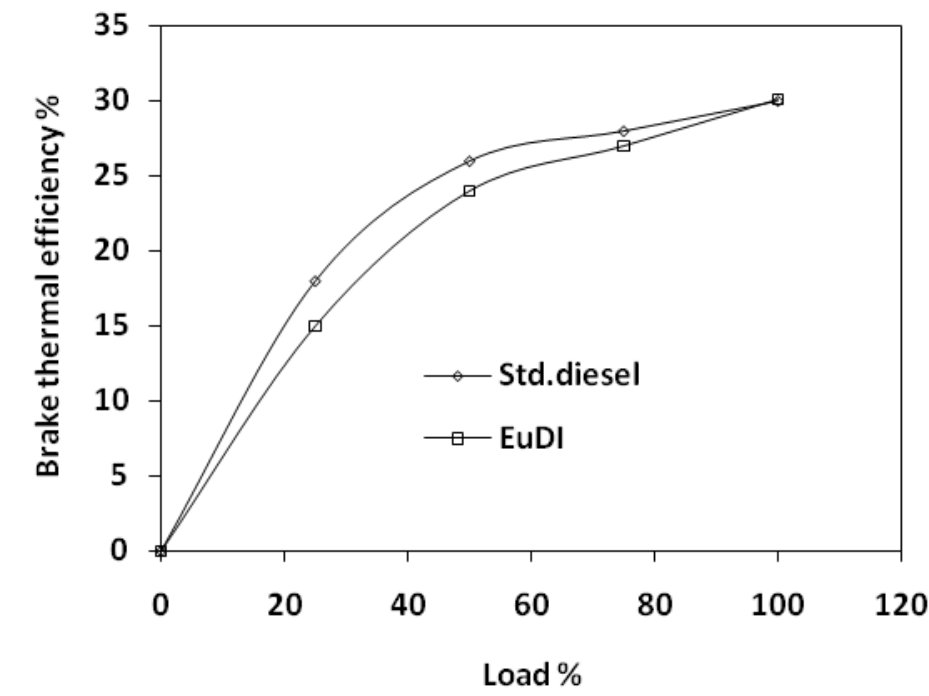

Figure 5. Variation of brake thermal efficiency with engine load 


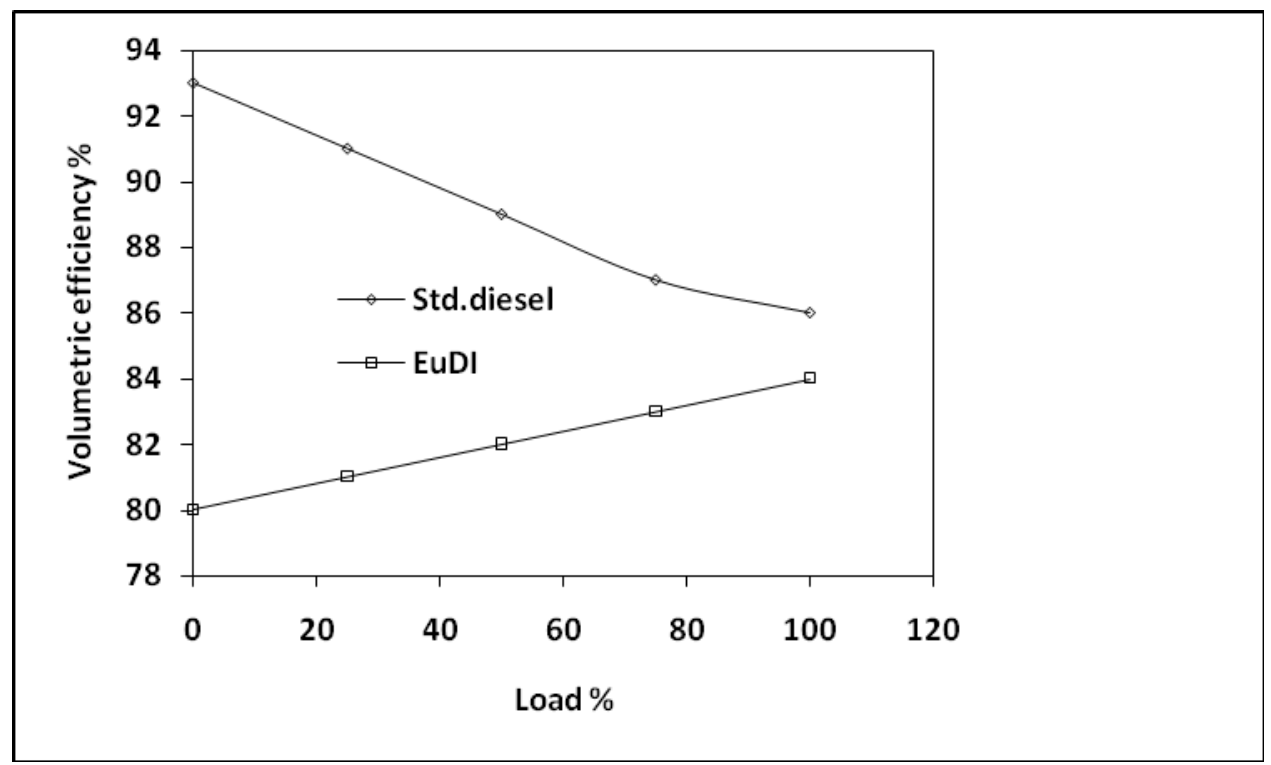

Figure 6. Variation of volumetric efficiency with engine load

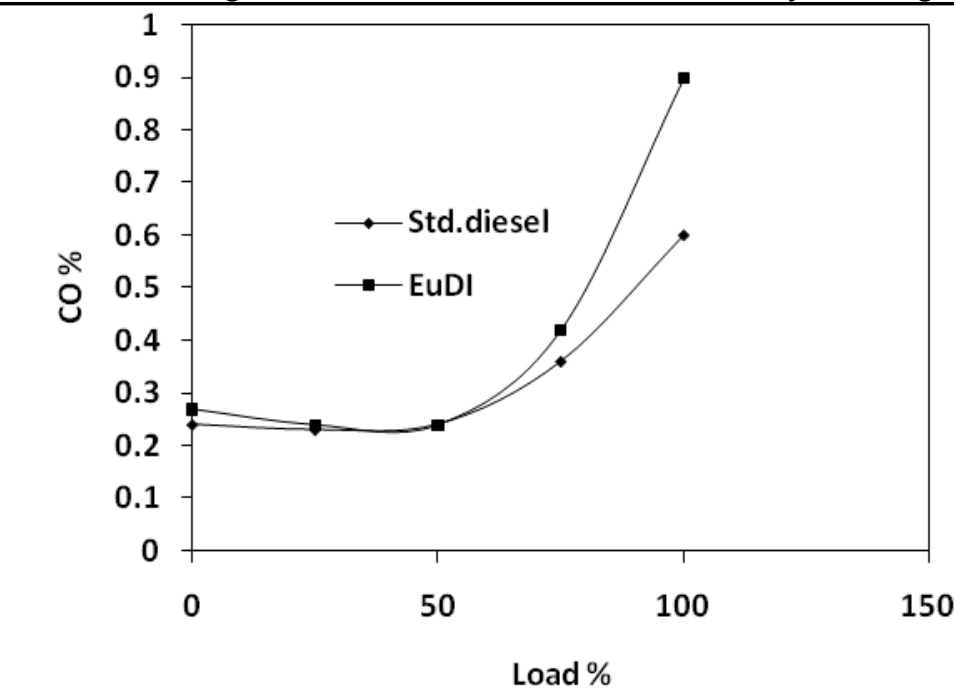

Figure 7. Variation of $\mathrm{CO}$ emission with engine load

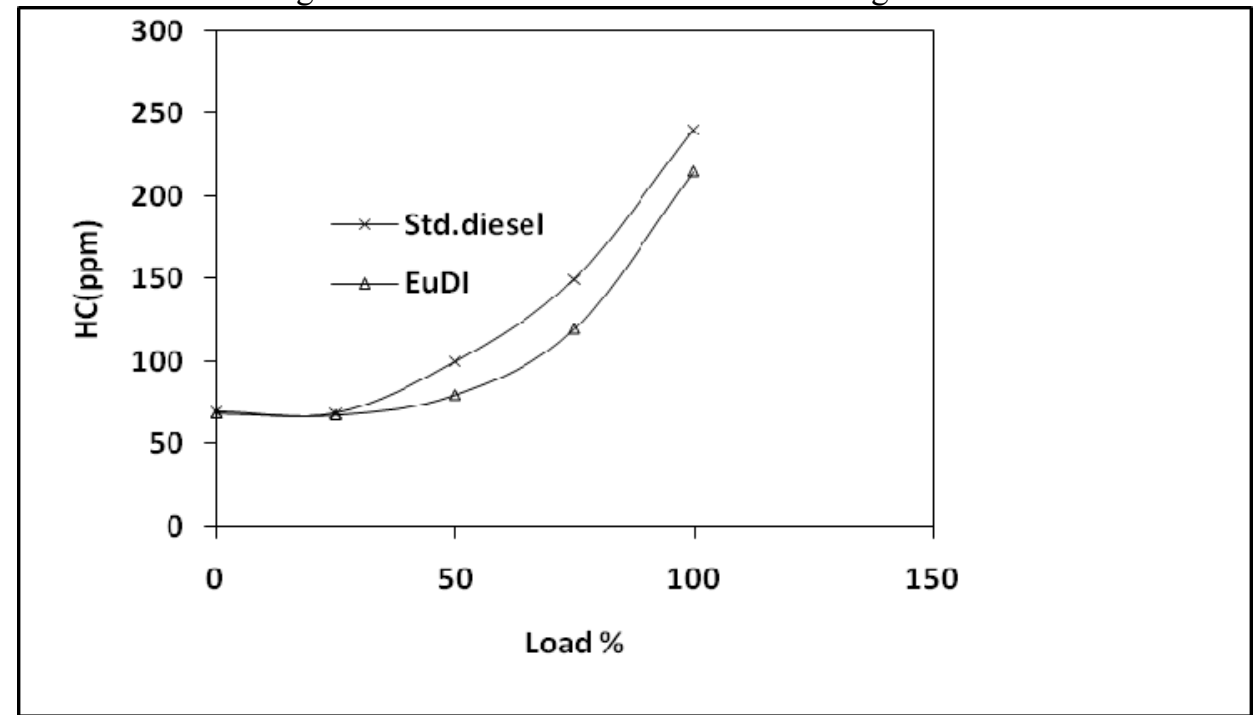

Figure 8. Variation of HC emission with engine load 


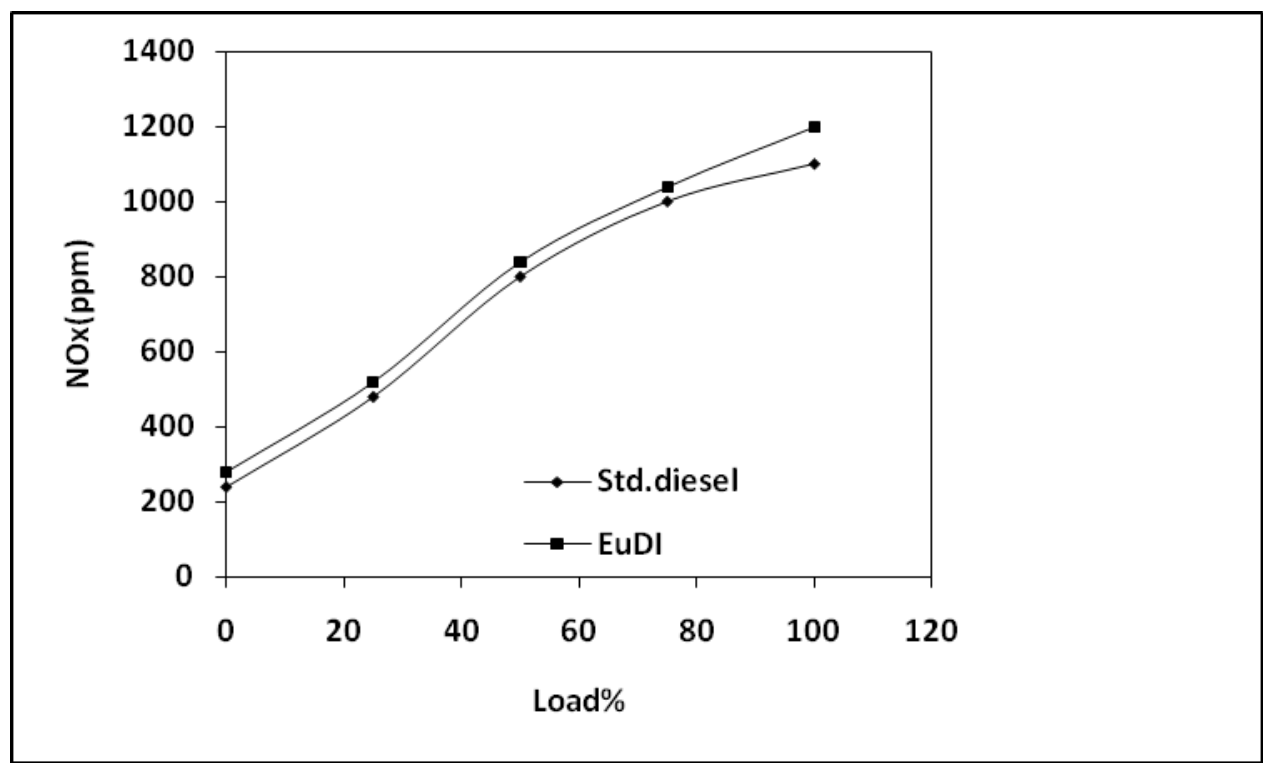

Figure 9. Variation of NOx emission with engine load

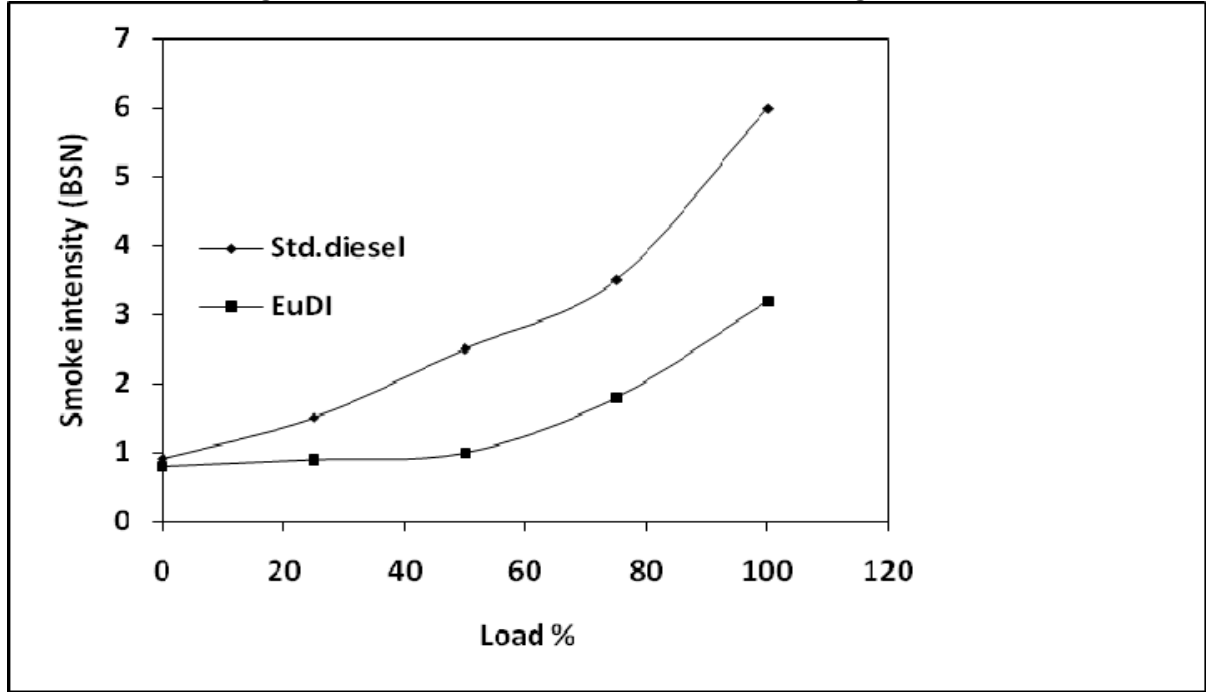

Figure 10. Variation of Smoke intensity with engine load

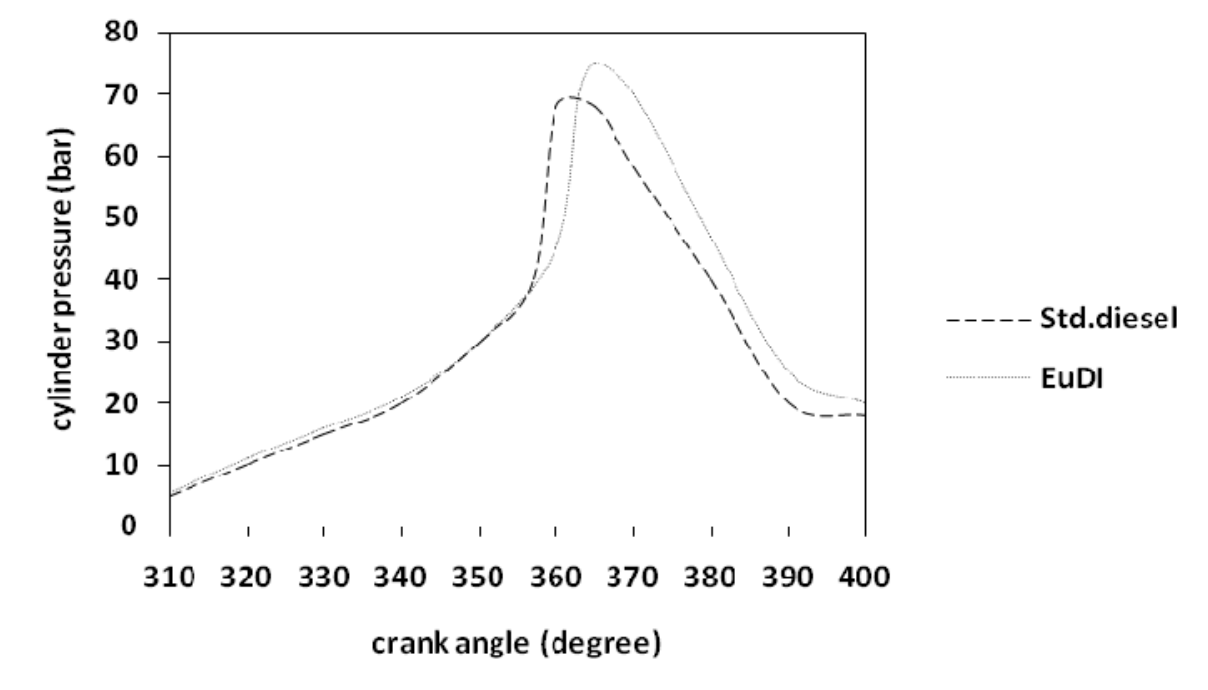

Figure 11. Variation of cylinder pressure with crank angle at full load 


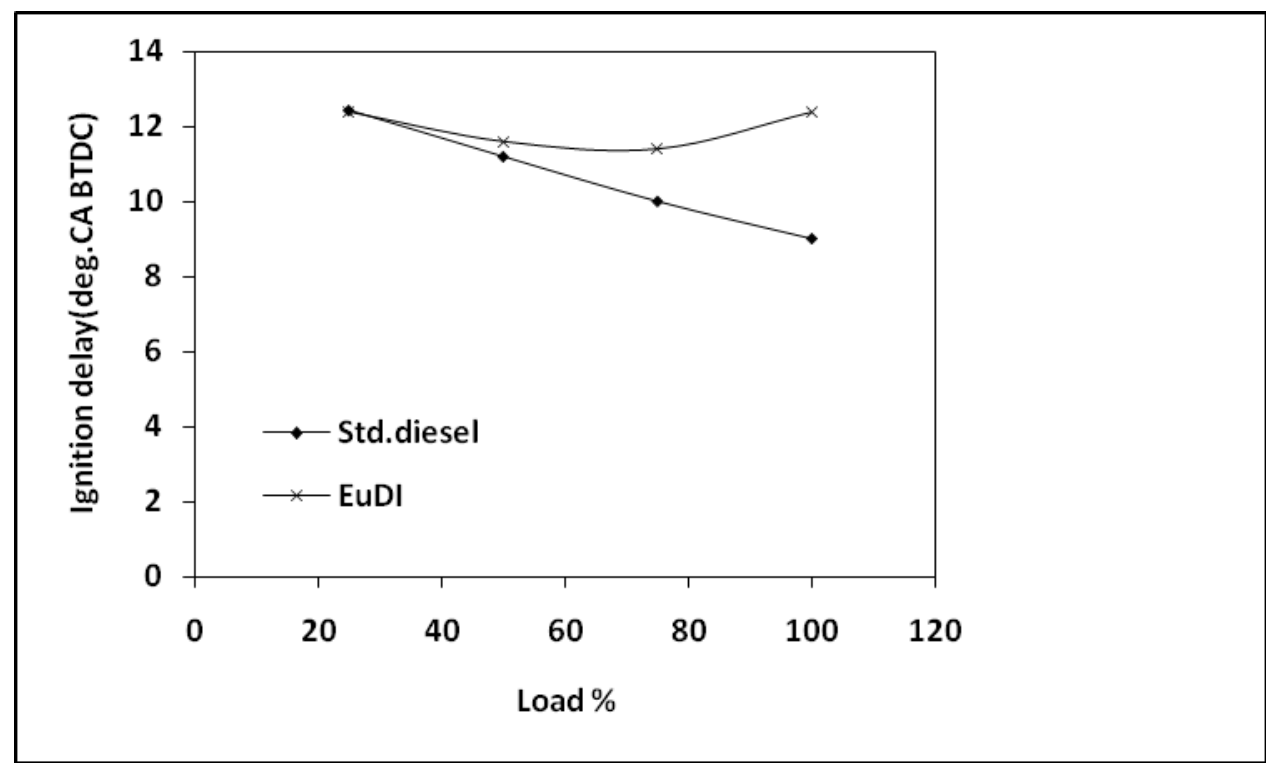

Figure 12. Variation of Ignition Delay with engine load

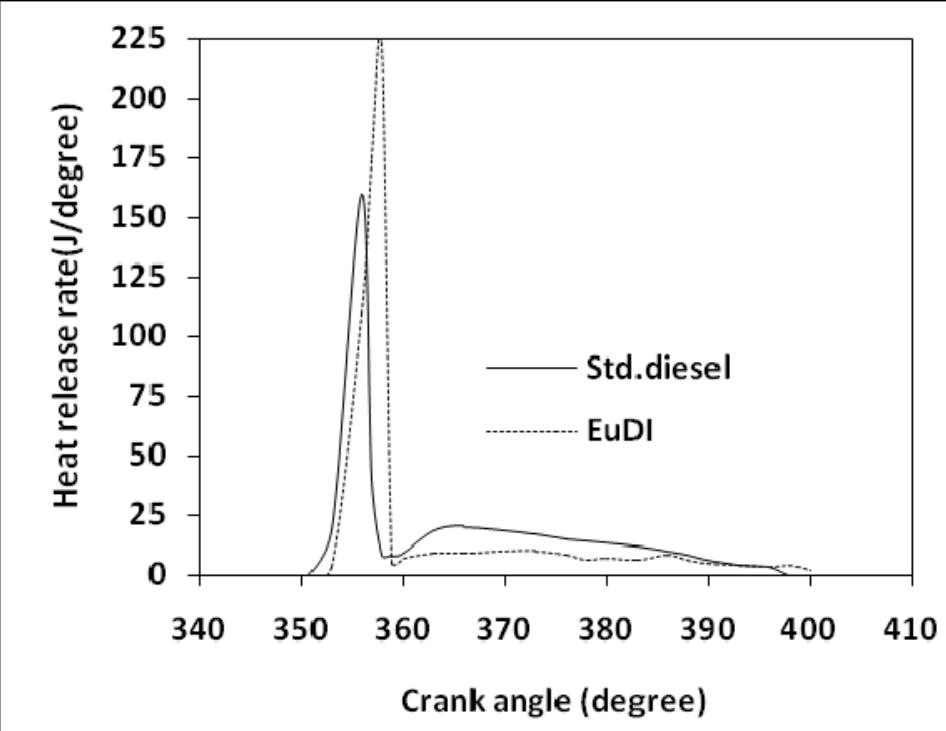

Figure 13. Variation of Net Heat Release Rate at full load 